\title{
Espaçamento entre linhas e horários de colheita na produção de biomassa e teor de óleo essencial de hortelã (Mentha arvensisL.)
}

\section{Line spacing and harvesting timesin biomass production and essential oil content of the peppermint (Mentha arvensis L.)}

\author{
Edgard Henrique Costa Silva ${ }^{1}$, Tiago Alves Ferreira ${ }^{1}$, Luiz Gustavo de Lima Guimarães ${ }^{1}$, \\ Edilson Nonato da Silva ${ }^{1}$, Valéria Gomes Momenté ${ }^{2}$ e Ildon Rodrigues do Nascimento ${ }^{1}$
}

${ }^{1}$ Curso de Agronomia; Universidade Federal do Tocantins; 77402-090; Gurupi - TO - Brasil. ${ }^{2}$ Curso de Engenharia de Alimentos; Universidade Federal do Tocantins; 77001-970; Palmas - TO - Brasil.

\begin{abstract}
The peppermint is a plant grown primarily for essential oil production and biomass, which can be influenced by environmental conditions. This study aimed to evaluate the biomass production and essential oil content of mint (MenthaarvensisL.) under the effect of different row spacing of planting and harvesting schedules. The experiment was conducted in a randomized block design with three replications and six treatments in a $2 x 3$ factorial, two row spacings $(0,40 \times 0,30 \mathrm{~m}$ and $0,60 \times 0,30 \mathrm{~m})$ and three harvest time $(6: 00$ to 7:00, 10:00 to 11:00 and 16:00 to 17:00). The characteristics evaluated were: total chlorophyll, temperature of leaves in harvest time $\left({ }^{\circ} \mathrm{C}\right)$, total fresh biomass of leaves $\left(t \mathrm{ha}^{-1}\right)$, total dry biomass of leaves $\left(t \mathrm{ha}^{-1}\right)$, total fresh biomass of shoot $\left(\mathrm{t} \mathrm{ha}^{-1}\right)$, total dry biomass

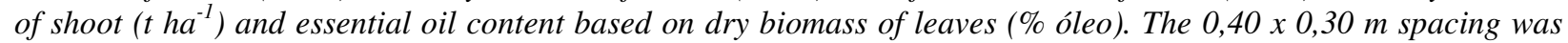
superior for the production of fresh biomass of leaves and shoots (3,05 and 4,8 tha-1, respectively) and dry biomass of leaves and shoots $(0,28$ and 0,5 tha-1, respectively). There was no effect on the timing of harvest or spacing on essential oil yield.
\end{abstract}

Key-words:MenthaarvensisL., planting density, oil yield

\section{INTRODUÇÃO}

A Mentha arvensis L., é uma planta aromática pertencente à família botânica Lamiaceae, conhecida popularmente como hortelã, hortelãverde, hortelã-comum, hortelã pimenta, menta ou hortelanzinho. É uma planta herbácea, semi-perene introduzida pelos imigrantes japoneses. A hortelã apresenta propriedades espasmolíticas, antivomitivas, carminativas, estomáticas e antihelmínticas quando utilizada por via oral e, antibacteriana, antifúngica e antiprurido, quando em uso tópico (Gruenwald et al., 2000; Mattos, 2000). O cultivo de plantas medicinais éuma alternativa rentáveis para áreas que não se mostram economicamente interessantes a cultivos de grandes culturas (Monteiro, 2009; Borsato e Feiden, 2011). Há um nicho específico de mercado que vem optando por consumir alimentos mais saudáveis e tratamentos médicos alternativos com produtos naturais (Monteiro, 2009).

O país já foi o maior produtor mundial de hortelã, porém ocorreu uma redução drástica na produção de Mentha spp.,devidoprincipalmente a problemas de fertilidade e manejo do cultivo em solo, uma vez que as condições nutricionais do solo são essenciais para o balanço entre acúmulo de biomassa e produção de óleo essencial, características indispensáveis para uma rentável produtividade de hortelã (Pauluset al.,2007; Valmorbida e Boaro, 2007).

Segundo Morais (2009), uma boa quantidade de plantas medicinais estão próximas ao seu estado silvestre, e por isso há uma forte interação com o ambiente, que por sua vez influencia no metabolismo secundário e consequentemente no teor e composição de óleos essenciais e afins. O

Author for correspondence: ildon@uft.edu.br

J. Biotec. Biodivers. v. 3, N.4: pp. 193-198, Nov. 2012 
óleo essencial dessa espécie é constituído principalmente por monoterpenos, atribuindo-se a estes as funções de defesa da planta contra herbivoria, agentes antimicrobianos e alelopáticos (Cardoso et al., 2001). O mentol e a mentona são os principais componentes do óleo e os de maior valor econômico, embora sejam conhecidos mais de 200 componentes presentes nos óleos do gênero Mentha(Tavish e Harris, 2002).

A indústria é consumidora de boa parte do que as plantas medicinais, aromáticas e condimentares produzem, e agregam valor através de fármacos, alimentos, cosméticos e recentemente de defensivos agrícolas alternativos à base de produtos naturais. (Monteiro, 2009; Aflatuni, 2005).

Estudos acerca do comportamento de plantas medicinais sob influência de diferentes condições ambientais na regulação biossintética do metabolismo secundário podem aumentar a produção de compostos de interesse, ou até mesmo elevar a eficiência na forma de exploração dos mesmos, o que remete a uma aplicação prática que justifica a busca de conhecimento sobre o assunto (Morais, 2009).

É de conhecimento comum que o espaçamento adotado em um cultivo pode influenciar não só o estande final de plantas, mas também caracteres produtivos que estão intimamente ligados a disponibilidade de espaço, água, luz e outros recursos. Existe uma relação direta entre o rendimento final da hortelã e o espaçamento entre as plantas, de forma que a biomassa total acumulada pelas plantas de hortelã varia com o espaçamento. Zheljazkov e Topalov (1996), Randhawa e Satinder (1996), Ineccoet al. (2003), Aflatuni (2005) e Monteiro (2009) verificaram influência de espaçamentos entre linhas em espécies de menta.Com base nesses resultados são fundamentais estudos que busquem viabilizar o cultivo de espécies com potencial para serem exploradas, respeitando-se as condições edafoclimáticas regionais, uma vez que a produção de princípios ativos pelas plantas pode ser intensamente afetada pelo ambiente de cultivo (Rohloffet al., 2005; David et al., 2006).

Aexemplo do que acontece em outros estados, a agricultura familiar, especialmente com o cultivo de plantas medicinais é uma importante atividade realizada pelos produtores do estado do Tocantins. Apesar desse potencial, a atividade ainda é carente de pesquisa e tecnologias com alternativas voltadas para esse segmento (Coelho et al., 2005).
O objetivo do trabalho foi avaliar a influência do espaçamento entre linhas de plantio e horário de colheita de plantas de hortelã-verde no acúmulo de biomassa total e no teor de óleo essencial, na região Sul do Estado do Tocantins.

\section{MATERIAL E MÉTODOS}

O trabalho foi realizado na área experimental da Universidade Federal do Tocantins - Campus Universitário de Gurupi, no Setor de Olericultura. Foram utilizadas plantas de hortelãverde(Menthaspicata L.),obtidas de matrizes do horto de plantas medicinais de Palmas - TO. Para a instalação do experimento, essas plantas foram multiplicadas em condição de casa de vegetação. $\mathrm{O}$ experimento foi conduzido no delineamento experimental de blocos ao acaso, com três repetições. Foram utilizadas combinações fatoriais constituídas de espaçamentos entre linhas $(0,40 \mathrm{~m}$ x 0,30 mcom densidade de plantas de 83333,3 por hectare e $0,60 \mathrm{~m} \times 0,30 \mathrm{~m}$ com 55555,6 plantas por hectare) e horários de colheita (06:00 às 07:00 horas; 10:00 às 11:00 horas e 16:00 às 17:00 horas). As mudas foram obtidas pelo enraizamento de estacas de 4 a $6 \mathrm{~cm}$ de comprimento. $\mathrm{Na}$ produção das mudas foram utilizadas bandejas de poliestireno expandido de 128 células e substrato composto de terra de barranco, esterco bovino e palha de arroz carbonizada na proporção de 1:1:1. As plantas foram transplantadas, aos 30 dias após plantio, para canteiros de $1 \mathrm{~m}$ de largura. Cada parcela foi dotada de cinco metros de comprimento, sendo utilizado como parcela útil plantas competitivas do centro das parcelas. $\mathrm{Na}$ adubação de plantio foi utilizado esterco bovino curtido na dosagem $1 \mathrm{kgm}^{-2}$ de canteiro, distribuído e incorporado nos canteiros no plantio e em cobertura aos 30 e 60 dias, após o transplante das mudas.A colheita foi realizada por ocasião do florescimento, sendo avaliado as seguintes características: clorofila total, temperatura de folhas no horário de colheita $\left(\mathrm{em}^{\circ} \mathrm{C}\right)$, biomassa fresca total de folhas $\left(\mathrm{t} \mathrm{ha}^{-1}\right)$, biomassa seca total de folhas $\left(\mathrm{t} \mathrm{ha}^{-1}\right)$, biomassa fresca total da parte aérea $\left(\mathrm{t} \mathrm{ha}{ }^{-1}\right)$, biomassa seca total da parte aérea $(\mathrm{t}$ $\mathrm{ha}^{-1}$ ) e teor de óleo essencial $(\%)$ com base na biomassa seca de folhas.A determinação da matéria seca foi feita em estufa com ventilação de ar forçada à $65^{\circ} \mathrm{C}$ atéatingir massa constante.

A extração do óleo essencial foi realizada através de hidrodestilação com aparelho do tipo Clevenger, usando amostras de 100 gramas de biomassa fresca de folhas em um balão de fundo 
redondo com capacidade para 2 litros, por 120 minutos contados após a fervura.O teor de óleo essencial (\%) foi calculado com base na biomassa seca dasfolhas. Para essa característica os valores foram transformados para $\sqrt{x+0,5}$. A clorofila totalfoi obtida através de clorofilômetro marca ClorofiLOG modelo CFL 1030, com medições expressas em na unidade Índice de Clorofila Falker (ICF), sendo unidades adimensionais (Falker, 2008). A temperatura das folhas no horário de colheita foi obtida através de um termômetro infravermelho portátil.As médias de cada repetição foram submetidos à análise de variância e as médias comparadas pelo teste de Tukey $(\mathrm{p}=0,05)$ utilizando o software SISVAR (Ferreira, 2008).

\section{RESULTADOS E DISCUSSÃO}

Para a característica biomassa fresca total de folhas houve diferença significativa com relação aos espaçamentos e horários de colheita (Tabela 1). O espaçamento $0,40 \mathrm{mx} 0,30 \mathrm{~m}$ proporcionou maior acúmulo de biomassa em todos os horários de colheita avaliados. A influência do horário de colheita para a biomassa fresca total de folhas pode ser explicada pela temperatura de folhas no horário de colheita 06:00 às 07:00 horas ter sido estatisticamente inferior aos demais horários avaliados dentro de cada espaçamento, com médias $25,73{ }^{\circ} \mathrm{C}$ para o espaçamento $0,40 \times 0,30 \mathrm{~m}$ e $24,95^{\circ} \mathrm{C}$ para $0,60 \times 0,30 \mathrm{~m}$ (Tabela 1 ), havendo assim menor evapotranspiração celular e por consequência maior umidade e massa absoluta.

A biomassa fresca total de parte aérea (Tabela 1) foi influenciada somente pelo espaçamento, sendo o espaçamento $0,40 \mathrm{~m} \quad \mathrm{x} \quad 0,30 \mathrm{~m} \quad \mathrm{o}$ mais adequado,proporcionando maiores valores médios. Essa característica não teve variação significativa para horário de colheita por ser constituídas da biomassa de folhas e caules, especialmente por que o caule não é passível de mudanças abruptas de umidade em temperaturas abaixo de $35^{\circ} \mathrm{C}$, fazendo com que a média não sofra variação no decorrer dos horários de avaliação.

$\mathrm{O}$ espaçamento $0,40 \times 0,30 \mathrm{~m}$ proporcionou maiores valores médios para biomassa seca total de folhas e biomassa seca total de parte aérea (Tabela 1), independente do horário de colheita, com média de $0,28 \mathrm{t} \mathrm{ha}^{-1} \mathrm{e} \quad 0,50 \mathrm{t} \mathrm{ha}^{-1}$, respectivamente, destacando assim que o cultivo mais adensado de hortelã-verde proporcionou maior acúmulo de biomassa, seja de folhas ou de parte aérea. Em acordo com Santos e Oliveira (1961), Marco et al. (2007) e Monteiro (2009) que testaram diferentes espaçamentos para Mentha arvensis L., capim citronela (Cymbopogon winterianus Jowitt.) e Mentha campestres Schur., respectivamente, e concluíram que dentre os espaçamento testados, aqueles mais adensados eram potencialmente melhores para as características avaliadas.

$\mathrm{Na}$ avaliação da biomassa considerou-se a densidade de plantas e, de acordo com Monteiro (2009), em função de o maior espaçamento possuir menor número de plantas por unidade de área, pode-se explicar sua menor produtividade quando os dados são apresentados em toneladas por hectare, por exemplo.

A clorofila total não foi influenciada pelos espaçamentos entre linhas e nem pelos horários de colheita. A temperatura de folhas no horário de colheita 06:00 às 07:00 foi estatisticamente inferior as demais dentro de cada espaçamento. Entre espaçamentos de plantios, apenas o horário de colheita 16:00 às 17:00 teve média diferente significativamente, $\operatorname{com} 33,7^{\circ} \mathrm{C}$ para $\mathrm{o}$ espaçamento $0,40 \times 0,30 \mathrm{~m}$.

Não houve diferença significativa para teor de óleo essencial entre os espaçamentos avaliados, porém o espaçamento $0,40 \times 0,30 \mathrm{~m}$ proporcionou maiores médias em todos os horários de colheita avaliados. $\mathrm{O}$ espaçamento menos adensado $(0,60 \mathrm{x}$ $0,30 \mathrm{~m})$ foi significativo para teor de óleo essencial em apenas no horário de colheita16:00 às 17:00 horas. (Tabela 1). 
Tabela 1. Biomassa fresca total de folhas $\left(\operatorname{tha}^{-1}\right)$, biomassa seca total de folhas $\left(\right.$ tha $\left.^{-1}\right)$, biomassa fresca total de parte aérea $\left(\right.$ tha $\left.^{-1}\right)$, biomassa seca total de parte aérea $\left(\right.$ tha $\left.^{-1}\right)$, clorofila total (ICF), temperatura da folha $\left({ }^{\circ} \mathrm{C}\right)$ no horário de colheita e teor de óleo essencial $(\%)$ com base na biomassa seca de folhas, em função de diferentes espaçamentos entre linhas e horários de colheitas em hortelã pimenta [Mentha arvensis L.]. Gurupi, TO, 2012.

\begin{tabular}{|c|c|c|c|}
\hline \multirow[b]{2}{*}{ Horários } & \multicolumn{2}{|c|}{$\begin{array}{l}\text { Biomassa fresca total de folhas }\left(\text { tha }^{-1}\right) \\
\text { Espaçamento }\end{array}$} & \multirow[b]{2}{*}{ Média Geral } \\
\hline & $0,40 \times 0,30 \mathrm{~m}$ & $0,60 \times 0,30 \mathrm{~m}$ & \\
\hline 06:00 às 07:00 & $3,85 \mathrm{Aa}$ & $2,41 \mathrm{Ab}$ & 3,13 \\
\hline 10:00 às 11:00 & $2,98 \mathrm{Ba}$ & $1,44 \mathrm{Bb}$ & 2,21 \\
\hline $16: 00$ às $17: 00$ & $2,32 \mathrm{Ba}$ & $1,66 \mathrm{Bb}$ & 1,99 \\
\hline $\begin{array}{l}\text { Média Geral } \\
\text { C.V. }(\%)\end{array}$ & 3,05 & $\begin{array}{c}1,84 \\
13,58\end{array}$ & 2,44 \\
\hline \multicolumn{4}{|c|}{ Biomassa seca total de folhas $\left(\right.$ tha $\left.^{-1}\right)$} \\
\hline 06:00 às 07:00 & $0,19 \mathrm{Ca}$ & $0,18 \mathrm{Aa}$ & 0,18 \\
\hline 10:00 às 11:00 & $0,29 \mathrm{Ba}$ & $0,22 \mathrm{Ab}$ & 0,25 \\
\hline $16: 00$ às $17: 00$ & $0,36 \mathrm{Aa}$ & $0,23 \mathrm{Ab}$ & 0,29 \\
\hline $\begin{array}{l}\text { Média Geral } \\
\text { C.V. }(\%)\end{array}$ & $\mathbf{0 , 2 8}$ & $\begin{array}{c}0,21 \\
12,59\end{array}$ & $\mathbf{0 , 2 4}$ \\
\hline \multicolumn{4}{|c|}{ Biomassa fresca total de parte aérea $\left(\right.$ tha $\left.^{-1}\right)$} \\
\hline 06:00 às 07:00 & $5,05 \mathrm{Aa}$ & $3,51 \mathrm{Ab}$ & 4,28 \\
\hline 10:00 às 11:00 & $4,27 \mathrm{Aa}$ & $2,82 \mathrm{Ab}$ & 3,55 \\
\hline $16: 00$ às $17: 00$ & $5,07 \mathrm{Aa}$ & $3,51 \mathrm{Ab}$ & 4,29 \\
\hline $\begin{array}{l}\text { Média Geral } \\
\text { C.V. }(\%)\end{array}$ & 4,80 & $\begin{array}{l}3,28 \\
17,00\end{array}$ & 4,04 \\
\hline \multicolumn{4}{|c|}{ Biomassa seca total de parte aérea $\left(\right.$ tha $\left.^{-1}\right)$} \\
\hline 06:00 às 07:00 & $0,49 \mathrm{Aa}$ & $0,39 \mathrm{Ab}$ & 0,44 \\
\hline 10:00 às 11:00 & $0,53 \mathrm{Aa}$ & $0,36 \mathrm{Ab}$ & 0,44 \\
\hline $16: 00$ às $17: 00$ & $0,47 \mathrm{Aa}$ & $0,33 \mathrm{Ab}$ & 0,40 \\
\hline $\begin{array}{l}\text { Média Geral } \\
\text { C.V. }(\%)\end{array}$ & $\mathbf{0 , 5 0}$ & $\begin{array}{r}\mathbf{0 , 3 6} \\
\mathbf{8 , 0 1} \\
\end{array}$ & $\mathbf{0 , 4 3}$ \\
\hline \multicolumn{4}{|c|}{ Clorofila total (ICF) } \\
\hline 06:00 às 07:00 & $31,03 \mathrm{Aa}$ & $30,00 \mathrm{Aa}$ & 30,51 \\
\hline 10:00 às 11:00 & $31,72 \mathrm{Aa}$ & $31,15 \mathrm{Aa}$ & 31,43 \\
\hline $16: 00$ às $17: 00$ & $29,63 \mathrm{Aa}$ & $28,59 \mathrm{Aa}$ & 29,11 \\
\hline $\begin{array}{c}\text { Média Geral } \\
\text { C.V. }(\%)\end{array}$ & 30,79 & $\begin{array}{c}29,91 \\
11,28\end{array}$ & 30,35 \\
\hline \multicolumn{4}{|c|}{ Temperatura de folhas $\left({ }^{\circ} \mathrm{C}\right)$} \\
\hline 06:00 às 07:00 & $25,73 \mathrm{Ba}$ & $24,95 \mathrm{Ba}$ & 25,34 \\
\hline 10:00 às 11:00 & $31,67 \mathrm{Aa}$ & $30,63 \mathrm{Aa}$ & 31,15 \\
\hline $16: 00$ às $17: 00$ & $33,70 \mathrm{Aa}$ & $29,60 \mathrm{Ab}$ & 31,65 \\
\hline $\begin{array}{l}\text { Média Geral } \\
\text { C.V. }(\%)\end{array}$ & 30,37 & $\begin{array}{l}28,39 \\
5,71\end{array}$ & 29,38 \\
\hline \multicolumn{4}{|c|}{ Óleo Essencial (\%) ${ }^{1}$} \\
\hline 06:00 às 07:00 & $0,80 \mathrm{Aa}$ & $0,72 \mathrm{Aa}$ & 0,76 \\
\hline $10: 00$ às $11: 00$ & $0,81 \mathrm{Aa}$ & $0,79 \mathrm{Aa}$ & 0,80 \\
\hline $16: 00$ às $17: 00$ & $0,86 \mathrm{Aa}$ & $0,72 \mathrm{Ab}$ & 0,79 \\
\hline $\begin{array}{l}\text { Média Geral } \\
\text { C.V. }(\%)\end{array}$ & $\mathbf{0 , 8 2}$ & $\begin{array}{l}0,74 \\
8,55\end{array}$ & $\mathbf{0 , 7 8}$ \\
\hline
\end{tabular}


As médias superiores do teor de óleo essencial para o espaçamento $0,40 \quad$ x $0,30 \mathrm{~m}$ estão diretamente relacionados com o desempenho da cultura nessa mesma condição para as características de biomassa fresca e seca total de folhas, onde os índices são independentes, porém correlatos.Monteiro (2009) verificou maiores produtividades de óleo essencial em duas épocas de colheita, com média de 199,48 $\mathrm{L} \mathrm{ha}^{-1}$ de óleo essencial no espaçamento mais adensado para a cultura da MenthacampestrisSchur. Em trabalho semelhante, Souza et al. (2006), observaram melhores rendimentos de óleo essencial para MenthapiperitaL. no período de 07:00 às 12:00 da manhã, sob cultivo hidropônico, nas condições climáticas de Campinas - SP, os teores de óleo essencial observados variaram de $0,71 \%$ e $1,33 \%$.

$\mathrm{O}$ espaçamento de $0,40 \times 0,30 \mathrm{~m}$ proporcionou maiores valores de biomassa fresca e seca de folhas e parte aérea. Quando o objetivo for rendimento de óleo obtido a partir das folhas, a colheita das folhas pode ser feita em qualquer horário do dia.

\section{RESUMO}

A hortelã é uma planta cultivada principalmente visando produção de óleo essencial e de biomassa, os quais podem ser influenciados por condições ambientais. O objetivo do trabalho foi avaliar a produção de biomassa e teor de óleo essencial de hortelã (Mentha arvensis L.) sob o efeito de diferentes espaçamentos entre linhas de plantio e horários de colheita. $\mathrm{O}$ experimento foi conduzido em delineamento de blocos casualizados com três repetições e seistratamentos, em um esquema fatorial $2 \times 3$, dois espaçamentos entre linhas $(0,40 \mathrm{~m}$ x $0,30 \mathrm{~m} \mathrm{e} 0,60 \mathrm{~m}$ x $0,30 \mathrm{~m})$ e três horários de colheita (6:00 às 7:00 horas; 10:00 às 11:00 horas e 16:00 às 17:00 horas). As características avaliadas foram: clorofila total, temperatura de folhas no horário de colheita $\left({ }^{\circ} \mathrm{C}\right)$, biomassa fresca total de folhas $\left(\mathrm{t} \mathrm{ha}^{-1}\right)$, biomassa seca total de folhas $\left(\mathrm{t} \mathrm{ha}{ }^{-1}\right)$, biomassa seca total de parte aérea $\left(\mathrm{t} \mathrm{ha}^{-1}\right)$, biomassa seca total de parte aérea $\left(\mathrm{t} \mathrm{ha}^{-1}\right)$ e teor de óleo essencial (\%) com base na biomassa seca de folhas. O espaçamento de $0,40 \times 0,30 \mathrm{~m}$ foi superior para produção de biomassa fresca de folhas e parte aérea $\left(3,05\right.$ e 4,8 $\mathrm{t} \mathrm{ha}^{-1}$, respectivamente) e biomassa seca de folhas e parte aérea $\left(0,28\right.$ e $0,5 \mathrm{t} \mathrm{ha}^{-1}$, respectivamente). Não houve efeito do horário de colheita ou de espaçamento no rendimento de óleo essencial.

Palavras-chave:Mentha arvensis L., densidade de plantio, rendimento de óleo

\section{REFERÊNCIAS}

Aflatuni, A.The yield and essential content of mint (Mentha ssp) in northern Ostrobothnia.Dissertação (Departamento de Biologia) - Universidade de Oulu, Finlândia, 2005.

Borsato, A. V. e Feiden, A. (2011), Biodiversidade Funcional e as Plantas Medicinais, Aromáticas e Condimentares. Documentos 119, Embrapa Pantanal.

Cardoso, M. G.; Shan, A. Y. K. V.; Pinto, J. E. B. P.; Filho, N. D.; Bertolucci, S. K. V. (2001),Metabólitos secundários vegetais: visão geral química e medicinal. 1. Ed. Lavras: Universidade Federal de Lavras.

Coelho, F.B.R.; Dal Belo, C.H.; Lolis, S.F.; Santos, M.G. (2005), Levantamento etnofarmacológico realizado na comunidade Mumbuca localizada no Jalapão - TO. Revista Eletrônica de Farmácia, 2, 52-55.

David, E. F. S.;Boaro, C.S.F.; Marques, M.O.M. (2006), Rendimento e composição do óleo essencial de Mentha piperita L., cultivada em solução nutritivacom diferentes níveis de fósforo. Revista Brasileira de Plantas Medicinais,8, 183188.

Falker Automação Agrícola Ltda. Manual do medidor eletrônico de teor clorofila (ClorofiLOG/CFL 1030). Porto Alegre, Falker Automação Agrícola. 2008.33p

Ferreira, D. F. (2008), SISVAR: um programa para análises e ensino de estatística. Revista Symposium (Lavras), 6, 36-41.

Gruenwald, J.; Bendler, T.; Jaenicke, C. (2000), Physicians Desk References (PDR) for herbal medicines.2. Ed.Montvale: Medical Economics Company.

Inneco, R.; Cruz, G.F.; Vieira, A.V.; Mattos, S.H.; Chaves, F.C.M. (2003), Espaçamento, época e número de colheitas em hortelã rasteira (Mentha $x$ villosa Huds). Revista Ciência Agronômica, 34, 247-251.

Marco, C.A.; Inecco, R.; Mattos, S.H.; Borges, N.S.S.; Filho, S.M. (2007), Influência de espaçamento, altura e época de corte no 
rendimento da biomassa e óleo essencial na cultura de capim citronela (Cymbopogum winterianus Jowitt.). Revista Ciência Agronômica, 37, 32-36.

Mattos, S.H. Estudos fitotécnicos da Mentha arvensis L.var.piperacens Holmes como produtora de mentol no Ceará. Tese (Doutorado em Fitotecnia) - Universidade Federal do Ceará, 2000.

Monteiro, R. Desenvolvimento de menta e produção de óleo essencial sob diferentes condições de manejo. Dissertação (Mestrado em Agronomia) - Universidade Federal do Paraná, 2009.

Morais, L.A.S. (2009), Influência dos fatores abióticos na composição química dos óleos essenciais. Horticultura Brasileira, 27, 50-63.

Paulus, D.; Medeiros, S. L. P.; Santos, O. S.; Manfron, P. A.; Paulus, E.;Fabbrin, E. (2007), Teor e qualidade do óleo essencial de menta (Mentha arvensisL.) produzida sob cultivo hidropônico e em solo. Revista Brasileira de Plantas Medicinais, 9, 80-87.

Randhawa, G. e Satinder, K. (1996), Optimization of harvesting time and row spacing for the quality oil in cornmint (Mentha arvensis L) varieties.Acta Horticulturae, 426, 615-622.

Souza, W. P.; Queiroga, C. L.; Sartoratto, A.; Honório, S. L. (2006), Avaliação do teor e da composição química do óleo essencial de Mentha piperita L. Huds durante o período diurno em cultivo hidropônico. Revista Brasileira de Plantas Medicinais, 8, 108-111.

Santos, S. R. e Oliveira, V. G. (1961), Espaçamento para menta (Mentha arvensis L.) Resultados experimentais do período de 1943-44 a 1950-51. Bragantia, 20, 701-709.

Rohloff, J.; Dragland, S.; Mordal, R.; Iversen, T. H. (2005), Effect of harvest time and drying method on biomass production, essential oil yield, and quality of peppermint (Mentha $x$ pipeitaL.). Journal of Agricultural and Food Chemistry,53, 4143-4148.

Tavish, H. M. e Harris, D. An economic study of essential oil production in the UK: a case study comparing non-UK lavander/lavandin production and peppermint/spearmint production with UK production techniques and costs. (2002), In: Government Industry, Forum for Non-Food Crops. Edinburg, The Scotch Parlament.

Valmorbida, J. e Boaro, C. S. F. (2007), Growth and development of Mentha piperita $\mathrm{L}$. in nutrient solution as affected by rates of potassium. Brazilian Archives of Biology and Technology, 50, 379-384.

Zheljazkov, V. e Topalov, V. (1996), Effect of planting time and density on yields from rooted mint cuttings. Journal of Herbs, 4, 15-24. 